\title{
ANALISIS LAYANAN REPOSITORI UNIVERSITAS DIPONEGORO BERDASARKAN AKSESIBILITAS, TAMPILAN, DAN ISI: UPAYA PEMBERDAYAAN REPOSITORI BERBASIS RISET
}

\author{
Jumino $^{1 *}$, Sri Ati Suwanto ${ }^{2}$ \\ ${ }^{1,2}$ Fakultas Ilmu Budaya, Universitas Diponegoro \\ *Korespondensi: jumino@live.undip.ac.id
}

Diajukan: 21-12-2018; Direview: 25-03-2019; Diterima: 16-05-2019; Direvisi: 28-10-2019

\begin{abstract}
This study aims to analyze how the appearance, accessibility, contents, and to empower the IR UNDIP. The research method used is qualitative by using in-depth interviews, observation, documentation, and FGD as a method of data collection. Data processing is done by reducing and verifying data. The results showed that: (1) the display used by IR UNDIP was considered too simple, monotonous, and less user friendly; (2) the contents of the repository, must be complete and varied, according to the study programs available at the university; 3) increasing the ease of access of IR UNDIP needs to be considered, by providing instructions on how to $\log$ in by users and to increase the speed of wifi.
\end{abstract}

\begin{abstract}
ABSTRAK
Penelitian ini bertujuan untuk menganalisis bagaimana tampilan, aksesibitas, konten, dan untuk memberdayakan IR UNDIP. Metode penelitian yang digunakan adalah metode kualitatif dengan menggunakan wawancara mendalam, observasi, dokumentasi, dan FGD sebagai metode pengumpulan data. Pengolahan data dilakukan dengan reduksi dan verifikasi data. Hasil penelitian menunjukkan: 1) tampilan yang digunakan oleh IR UNDIP dinilai terlalu sederhana, monoton, dan kurang user friendly; 2) konten repositori harus lengkap dan beragam, sesuai dengan program studi yang ada di universitas; 3) peningkatan kemudahan akses Repositori UNDIP perlu diperhatikan, dengan memberikan petunjuk log in oleh pengguna dan meningkatkan kecepatan wifi.
\end{abstract}

Keywords: Institution repository; Research services; Accessibility; E-library; Academic library

\section{PENDAHULUAN}

Kemajuan teknologi informasi telah mempengaruhi kemajuan di berbagai bidang ilmu dan menggeser budaya temu kembali Informasi di perpustakaan. Pemakai yang semula mencari informasi melalui buku-buku teks dan majalah tercetak, mulai bergeser mencari dengan menggunakan web, tak terkecuali pemakai Perpustakaan Universitas Diponegoro (UNDIP). Mulai tahun 2005, UNDIP telah memulai electronic library (e-library). E-library menurut Oppenheim dalam Rowley (1998), yaitu: “...an organized and managed collection of information in a variety of media (text, still image, moving image, sound or combinations thereof). The collection is organized and managed for the benefit of an actual or potential user population, and in particular is structured for easy access to its contents. Typically, such an electronic library will include a number of search or navigation aids that will both operate within that particular library and allow access to other collection of information connected by networks worldwide".

Pernyataan di atas bermakna kumpulan informasi yang terkelola dalam berbagai media (teks, gambar diam, gambar bergerak, dan/atau suara). Koleksi ini diatur dan dikelola untuk kepentingan populasi pengguna aktual atau potensial, dan secara khusus disusun untuk kemudahan akses kontennya. Perpustakaan elektronik akan mencakup sejumlah pencarian atau 
alat bantu navigasi yang beroperasi di dalam perpustakaan dan memungkinkan akses ke informasi lain yang terhubung dengan jaringan global. Menurut Oppenheim, perpustakaan digital tidak akan mempunyai kemajuan jika tidak dihubungan dengan konsep jaringan.

Pada tahun 2009, E-library UNDIP berkembang menjadi perpustakaan digital. Menurut Waters (1998), perpustakaan digital adalah organisasi yang menyediakan sumber daya, termasuk staf khusus; memilih, menyusun, menawarkan akses intelektual; menginterpretasikan, mendistribusikan, menjaga integritas; dan memastikan persistensi seiring waktu koleksi karya digital sehingga siap dan tersedia secara ekonomi untuk digunakan oleh komunitas.

Berdasarkan data kunjungan Web Repositori Lembaga atau Institutional Repository (IR) UNDIP per-September 2016 (http://eprints.undip.ac.id), page load first time visit rata-rata berjumlah 5.917 dan returning visits hanya berjumlah 2.044 kali. Hal ini berarti hanya sepertiga pengunjung yang kembali menggunakan layanan repositori. Data dari Webometric Rank Asia pada Juli 2016, UNDIP memperoleh peringkat ke-4 di Asia-Pasific, peringkat ke-1 di Asia Tenggara dan peringkat ke-1 di Indonesia. Tetapi pada Januari 2017, peringkat Repositori UNDIP menurun menjadi peringkat ke-2 di Indonesia. Dengan demikian, pemberdayaan tingkat efektivitasnya sangat perlu untuk ditingkatkan. Salah satu langkah yang dapat dilakukan adalah menginventaris layanan dan koleksi, serta memberdayakan IR UNDIP untuk kegiatan riset (Universitas Diponegoro 2017).

Hasil-hasil penelitian yang selama ini dilakukan oleh para dosen dan peneliti sangat disayangkan jika hanya berhenti pada suatu hasil penelitian. Melalui pemberdayaan repositori diharapkan segala bentuk hasil penelitian yang ada dapat lebih dikembangkan dan diaplikasikan untuk kepentingan masyarakat. Berdasarkan uraian diatas, rumusan permasalahan penelitian ini yaitu: (1) bagaimanakah IR UNDIP dilihat dari segi kemudahan akses, tampilan, dan konten repositori?; dan (2) langkah-langkah apa saja yang perlu dilakukan untuk pemberdayaan IR UNDIP?

Tujuan umum penelitian ini adalah untuk mengevaluasi layanan repositori UNDIP serta mencari model langkah-langkah yang dilakukan untuk memberdayakan Repositori di Undip sebagai perguruan tinggi yang mengedepankan riset. Tujuan khusus dari penelitian ini adalah untuk mengidentifikasi aksesibilitas, tampilan dan konten repositori Undip yang mempunyai potensi untuk dikembangkan sebagai model Repositori bagi perguruan tinggi yang mengedepankan riset.

\section{TINJAUAN PUSTAKA}

\subsection{Repositori Lembaga (IR)}

Kata repositori dalam bahasa Inggris berarti sebagai tempat penyimpan (an)/gudang, sedang secara etimologi repositori berasal dari bahasa Latin repositoria atau repositorium, artinya tempat untuk menyimpan barang-barang berharga di dalam candi, di dalam gereja Romawi kuno dan lain-lain. IR masih mencakup kegiatan dalam menghimpun dan melestarikan koleksi digital yang merupakan hasil karya intelektual dari sebuah komunitas tertentu. IR seringkali dikaitkan dengan upaya untuk menghimpun karya-karya intelektual perguruan tinggi (Pendit, 2007).

Suwardi (2014) menyatakan bahwa IR mempunyai arti kata bersifat kelembagaan, yang berhubungan dengan lembaga. Menurut SPARC and Crow (2002), IR adalah "...is a-digital collections capturing and preserving the intellectual output of a single or multi-university community--provide a compelling response to two strategic issues facing academic institutions". Abrizah (2010) mengemukakan bahwa dalam universitas riset, konsep IR 
berdasarkan pada kontribusi pemangku kepentingan yang meliputi staf akademik dan staf nonakademik, mahasiswa pascasarjana dan sarjana. Masing-masing kelompok merupakan pengguna potensial dalam IR dan mereka berperan sebagai penulis, sangat penting untuk keberhasilan suatu IR.Tujuan IR adalah untuk menjamin berkembang dan melestarikan luaran ilmiah dan membuatnya terbuka untuk dapat diakses semua civitas akademika, sehingga semakin banyak anggota fakultas yang mendukung untuk menyediakan akses terbuka dari hasil penelitian universitas.

Keberhasilan suatu IR ditentukan oleh penggunaannya, hal tersebut dapat dilihat dari kontribusi penggunaan konten. Dalam perspektif perguruan tinggi, unit fakultas dan program studi biasanya mempunyai kontribusi besar dalam pemanfaatan IR, misalnya dengan membuat, melestarikan pengetahuan baru, memproduksi karya-karya ilmiah, dan berpartisipasi dalam proses kegiatan komunikasi ilmiah (Shearer dalam Abrizah, 2010).

\subsection{IR UNDIP}

Repositori menurut penjelasan web Repositori UNDIP adalah "UNDIP Institutional Repository (UNDIP-IR) is a digital collection of the University's intellectual or research output. Undip-IR centralizes, collects, preserves, and complies to open access concept of accessing collection of scholarly materials that showcases the research output of Diponegoro University communities. Diponegoro University Library and Study Program Librarians are responsible in establishing, collaborating, managing, maintaining and disseminating the content of Undip-IR" (http://eprints.undip.ac.id)". Dapat dikatakan bahwa IR UNDIP merupakan sebuah pangkalan data intelektual yang menyebarluaskan dan melestarikan seluruh pemikiran dan luaran hasil riset dari seluruh sivitas akademika di lingkungan UNDIP.

Mukaiyama dalam Pendit (2007) menyatakan bahwa ada tujuh teknologi dalam penerapan konsep perpustakaan digital, yaitu: (1) teknologi pengolahan konten, yaitu teknologi untuk membuat, menyimpan, dan menemukan kembali informasi digital, termasuk teknologi untuk konversi dokumen non-digital; (2) teknologi akses informasi, yaitu teknologi yang memungkinkan akses ke banyak jenis informasi dari berbagai tempat dan tak terbatas oleh waktu; (3) antarmuka manusia yang ramah, yaitu antarmuka yang memungkinkan peningkatan produktivitas intelek dalam bentuk fasilitas yang memungkinkan untuk berbagai pemakai melakukan berbagai cara mencari dan menghubungkan dokumen; (4) interoperabilitas, yaitu teknologi yang memungkinkan teknologi berbeda untuk "berkomunikasi" dalam lingkungan yang heterogen (sangat beragam); (5) skalabilitas, yaitu teknologi yang memperluas distribusi informasi dan meningkatkan jumlah pemakai dan kemungkinan akses; (6) pengembangan sistem terbuka (open access), yaitu teknologi yang memungkinkan standarisasi; (7) pengembangan sistem yang sangat fleksibel, yaitu teknologi yang dapat dengan cepat menyesuaikan diri dengan perkembangan sosial masyarakat

\section{METODE}

Penelitian ini menggunakan metode kualitatif. Menurut Sulistyo-Basuki (2006), penelitian kualitatif adalah penelitian yang bertujuan memperoleh gambaran seutuhnya mengenai suatu hal menurut pandangan orang yang diteliti. Kategori penelitian ini adalah studi kasus. Studi kasus merupakan kajian mendalam tentang peristiwa, lingkungan dan situasi tertentu yang mengungkapkan atau memahami suatu hal. Studi kasus cenderung menghasilkan kesimpulan suatu kekhususan yang dapat atau tidak dapat diterapkan pada situasi yang lebih umum (Sulistyo-Basuki, 2006). 
Pengumpulan data menggunakan metode wawancara, observasi partisipan, Forum Group Discussion (FGD), dan dokumentasi. Wawancara dilakukan terhadap 10 orang informan, dan 5 orang informan kunci untuk verifikasi. Metode pemilihan informan menggunakan teknik purposive sampling dengan jumlah sebanyak 10 orang pemakai IR UNDIP. Informan yang dipilih adalah pemakai yang aktif membuka IR UNDIP. Disamping itu, wawancara mendalam juga dilakukan terhadap 2 orang pustakawan untuk verifikasi, terutama menyangkut pemberdayaan IR UNDIP dari sisi pengelola (pustakawan) dan pengambil kebijakan (kepala perpustakaan). Analisis data dilakukan melalui tahapan sesuai dengan teori Matthew B Miles and Huberman (1992), yaitu: (1) kategorisasi dan reduksi data; (2) menyusun data dalam bentuk narasi; (3) interpretasi data; (4) pengambilan kesimpulan.

\section{HASIL DAN PEMBAHASAN}

IR merupakan lumbung pengetahuan pada sebuah lembaga, terlebih untuk suatu perguruan tinggi yang merupakan lembaga penghasil pengetahuan. Sebagai lumbung pengetahuan, IR seharusnya berfungsi sebagai sarana utama dokumentasi pengetahuan yang dihasilkan oleh perguruan tinggi. Mengingat pentingnya peran IR bagi eksistensi perguruan tinggi, lembaga harus memberikan perhatian pada kualitas IR.

Sebagai universitas riset, pada tahun 2020, UNDIP dituntut meningkatkan prestasinya lagi dalam hal webometrik IR, sebagaimana mendapatkan prestasi IR terbaik di Indonesia berdasarkan peringkat webometrics pada tahun 2015 dan 2016. Repositori ini merupakan salah satu sarana akses terbuka UNDIP dalam rangka memberikan informasi ilmiah ke masyarakat. Seiring dengan tujuan dari akses terbuka yang diterapkan, semakin luas spektrum penggunanya semakin baik pula kualitas dari repositori institusi.

Kenyamanan pengguna saat memanfaatkan repositori institusi sangat dipengaruhi oleh aspek konten, akses, dan kemudahan penelusuran. Konten, akses dan kemudahan penelusuran hanya dapat dinikmati oleh pengguna jika tampilannya mendukung repositori institusi. Kalau tampilan kurang mendukung, dapat berimbas pada display fasilitas repositori institusi yang berkaitan dengan ketiga hal tersebut.

Penelitian ini mengkaji kenyamanan pengguna ketika memanfaatkan IR UNDIP, dengan informan sejumlah 10 orang yang terdiri dari 8 orang mahasiswa dan 2 orang dosen (catatan: satu orang informan menyatakan jarang menggunakan IR UNDIP, ia hanya mengakses perpustakaan digital di http://digilib@undip.ac.id, sehingga tidak jadi dilibatkan).

\subsection{Kemudahan Akses}

Tahap pertama yang menjadi prioritas dalam pembenahan repositori adalah kemudahan akses, termasuk di dalamnya ketersediaan fasilitas penelusuran dan ragam konten dari repositori institusi. Kecepatan akses yang sangat bergantung pada koneksi sinyal internet yang sering lemah membuat informan merasa tidak nyaman karena membutuhkan waktu yang lama saat mengakses repositori. Selain kendala tersebut, fasilitas penelusuran yang belum memadai. Kurang presisinya hasil pencarian yang diperoleh para informan juga terkait dengan pengorganisasian informasi.

Berdasarkan keterangan informan, baik dosen maupun mahasiswa rata-rata mengakses IR UNDIP sebanyak satu kali dalam seminggu, informan menggunakan waktu akses selama 15 menit hingga satu jam. Jangka waktu akses yang relatif singkat dipengaruhi oleh faktor kemudahan akses, ketersediaan fasilitas penelusuran, dan ragam konten IR UNDIP. Informan mengeluhkan kecepatan akses yang bergantung pada koneksi sinyal internet yang lemah 
sehingga informan merasa tidak nyaman karena membutuhkan waktu yang lama saat mengakses IR UNDIP. Informan juga mengeluhkan tentang fasilitas penelusuran yang belum memadai. Keluhan terkait fasilitas penelusuran dinyatakan informan mahasiswa bahwa hasil pencarian kurang tepat, karena fasilitas penelusuran IR UNDIP belum terdapat fitur penelusuran lanjut (advanced search) yang memungkinkan penerapan sistem logika Boolean untuk membantu pengguna untuk memperoleh hasil pencarian yang lebih tepat.

Kurang tepatnya hasil pencarian yang diperoleh para informan juga terkait dengan pengorganisasian informasi. Pengorganisasian informasi dalam IR UNDIP sudah cukup baik, terutama pada fitur browsing, yang memungkinkan pengguna menelusur berdasarkan fakultas. Pengguna juga dapat menelusur berdasarkan subjek, tahun, dan tipe jurnal. Pengorganisasian konten berdasarkan subjek masih dirasa terlalu umum dan perlu difokuskan ke dalam sub-sub yang lebih khusus agar hasil penelusuran lebih tepat.

\subsection{Tampilan}

Tahapan kedua yang perlu mendapat prioritas adalah tampilan sebuah repositori institusi juga mempengaruhi akses pengguna terhadap pemakaian konten informasi yang terkandung didalamnya. Menemukan kembali informasi yang relevan sesuai dengan kebutuhan informasi dalam kegiatan penelusuran merupakan kegiatan yang mutlak harus dilakukan. Dari segi tampilan, tampilan default dari software e-prints dirasakan informan sudah cukup memadai dalam mengakomodir aktivitas penelusuran informasi. Namun terkait komposisi layout laman, informan mengatakan bahwa tampilan yang digunakan oleh IR UNDIP dinilai sederhana, monoton, dan kurang user friendly. Penataan tulisan yang berhimpit dan ukuran huruf yang terlalu kecil membuat informan kurang nyaman dalam menelusur informasi (Gambar 1). Tidak adanya menu petunjuk penggunaan juga menjadi faktor penyebab informan merasa bahwa IR UNDIP kurang user friendly, tidak ada fasilitas yang dapat membantu pengguna menemukan solusi saat menghadapai kendala dalam pemanfaatan IR UNDIP.

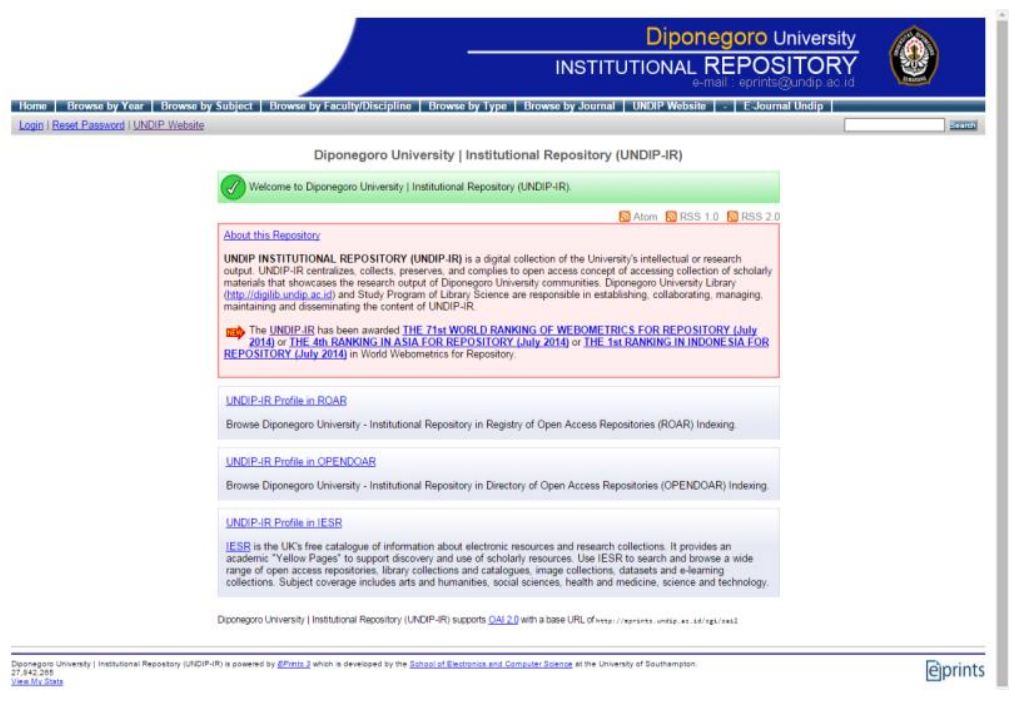

Gambar 1. Beranda website IR UNDIP

Menu penelusuran informasi pada sistem temu balik IR UNDIP ada dua pilihan, yaitu menu searching dan browsing. Menu searching dapat digunakan dengan cara: 1) menentukan 
kata kunci untuk diketikkan pada kolom yang tersedia; 2) menentukan kata kunci untuk membatasi hasil pencarian dengan tujuan agar tidak terlalu banyak muncul hasil penelusuran yang tidak sesuai dengan kebutuhan informasi pengguna. Menu browsing adalah menu yang disediakan untuk pengguna dengan berbagai pilihan menu penelusuran. Ketika ingin memanfaatkan menu browsing, pengguna ditawari beberapa pilihan, yakni penelusuran berdasarkan tahun terbit, subjek, fakultas/disiplin ilmu, tipe koleksi, dan judul publikasi jurnal.

Berdasarkan hasil wawancara dan FGD dengan informan terkait usaha temu kembali informasi, diketahui bahwa penelusuran dengan menggunakan menu search tidak efektif untuk menemukan kembali informasi, karena hasil yang dikeluarkan dalam penelusuran (recall) terlalu banyak dengan tingkat presisi yang rendah. Penyebabnya adalah sistem indeksasi yang dilakukan oleh sistem temu kembali informasi IR UNDIP tidak dapat dibatasi sehingga mengindeks keseluruhan teks yang diunggah dalam sistem tersebut.

Sebagai manifesto atau wujud komunikasi ilmiah di IR UNDIP telah dipublikasikan berbagai terbitan institusi. Hal tersebut berguna agar lintas perguruan tinggi dapat saling belajar dan mengetahui perkembangan penelitian yang sedang atau telah dilakukan oleh perguruan tinggi tersebut. Dalam kasus IR UNDIP, banyak terbitan institusi lembaga yang diunggah ke IR UNDIP tidak dapat diakses konten fulltext-nya. Pengguna hanya dapat mengakses metadata dan abstrak terbitan. Hal tersebut dapat menghambat proses komunikasi ilmiah karena setiap pengguna hanya membaca abstraknya saja. Apabila pengguna ingin membaca secara lengkap keseluruhan teks maka mereka harus masuk menggunakan username dan password keanggotaan IR UNDIP. Kelemahannya adalah tidak adanya penjelasan secara tertulis dalam halaman IR UNDIP mengenai cara untuk mendaftar sebagai anggota.

\subsection{Konten}

Koleksi diperluas subjeknya sesuai dengan bidang keilmuan di UNDIP dan kontennya diperbarui secara berkala (sesuai dengan saat wisuda mahasiswa). Hal ini perlu ditindaklanjuti untuk merealisasikan model sesuai dengan tahapan yang sesuai dengan kebutuhan pengguna. Beberapa kekurangan yang terdapat pada tampilan laman IR UNDIP. Informan dosen dan mahasiswa menyatakan konten IR UNDIP belum dapat memenuhi harapan pengguna. Selain itu, kuantitas, ragam, dan keterbaruan konten menjadi masalah utama para informan. Mereka menyatakan bahwa konten yang mereka harapkan lebih mudah diperoleh melalui mesin pencari biasa seperti Google Cendikia. Beberapa informan menyatakan bahwa isi dari IR UNDIP belum memenuhi harapan, karena untuk jenis dan subjek artikel bidang Ilmu-Ilmu Sosial \& Humaniora belum variatif.

Alasan lain adalah adanya keterlambatan perkembangan terbitan institusi yang di upload. Banyak skripsi dua tahun terakhir belum muncul pada hasil pencarian. Hal yang sama dikatakan informan dari kelompok dosen bahwa informasinya kurang lengkap, tidak ada petunjuk tentang cara mendaftar IR UNDIP. Informan dari mahasiswa menyatakan bahwa sudah cukup memenuhi harapan, hanya pembaharuan koleksi masih lambat dan tidak konsisten dalam penggunaan bahasa (Indonesia dan Inggris). 


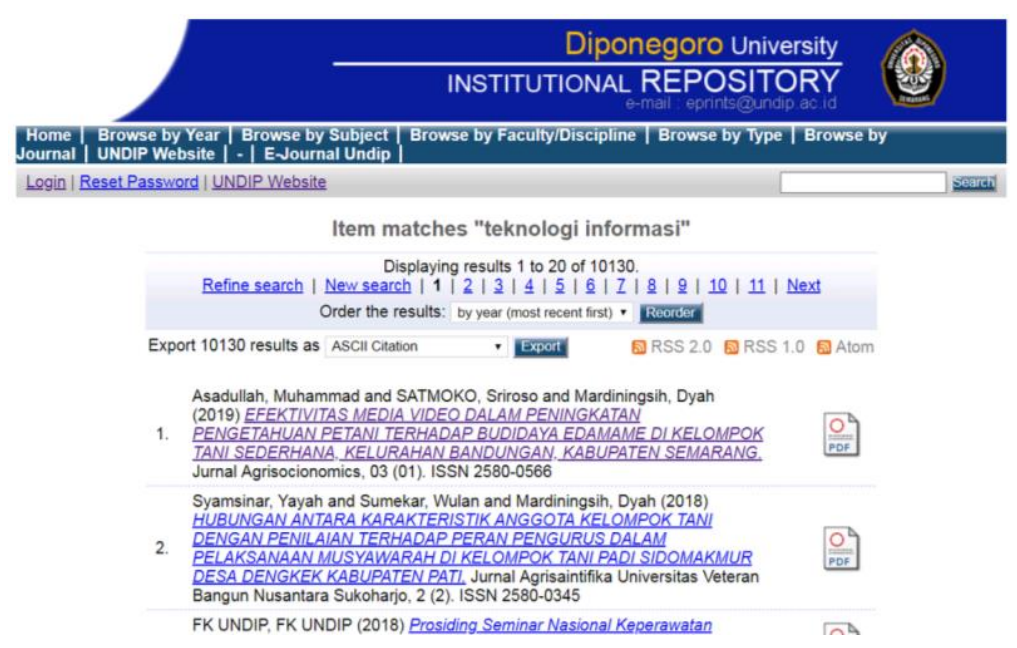

Gambar 2. Tampilan pencarian dari subjek

Berdasarkan Gambar 2 terlihat bahwa pencarian dengan kata "teknologi informasi" ditemukan hasil penelusuran yang kurang tepat pada menu browse by subject, misalnya "Peran Pengurus dalam Pelaksanaan Musyawarah di Kelompok Usaha Tani...”. Menurut para informan jenis koleksi dari repositori seharusnya mudah ditemukan, bervariasi, dan konsisten dengan submenu yang dinyatakan di atas menu. Subjek lebih bervariasi dengan memberikan beberapa alat pencarian informasi, seperti Boolean Logic. sehingga lebih tepat dan sesuai dengan kebutuhan pengguna. Penyedia repositori juga harus mencari cara termudah untuk mempersempit hasil pencarian informasi melalui cara lain.

\section{KESIMPULAN}

IR UNDIP yang menjadi salah satu repositori perguruan tinggi dalam operasionalnya masih membutuhkan pengembangan. Tampilan IR UNDIP perlu mendapat prioritas utama dan perlu di-update fiturnya agar tidak terlalu sederhana, monoton, dan kurang user friendly. Konten IR juga harus lengkap dan spesifik sesuai dengan program studi yang ada di universitas. Lembaga perlu melakukan pembenahan IR UNDIP dengan memperhatikan kemudahan dan kecepatan akses; ketersediaan fasilitas penelusuran dan ragam konten; fasilitas penelusuran; serta pengorganisasian konten informasi. Terkait hal tersebut, Perpustakaan UNDIP perlu: (1) melakukan perbaikan penampilan repositori yang lebih dinamis dan bervariasi; (2) memperbaiki sistem indeksasi agar dapat dipersempit sesuai dengan topik dan bidang keilmuan; (3) menambah subjek sesuai bidang ilmu; (4) memberikan panduan untuk menjadi anggota IR UNDIP.

\section{UCAPAN TERIMA KASIH}

Peneliti ingin mengucapkan terima kasih kepada: Dekan Fakultas Ilmu Budaya yang telah memberikan dana penelitian; Kepala Perpustakaan UNDIP yang telah memberikan kesempatan kepada peneliti untuk melakukan penelitian; Ibu Ika Krismayani yang telah membantu mengumpulkan data; serta Pustakawan UNDIP yang telah bersedia menjadi informan penelitian. 


\section{DAFTAR PUSTAKA}

Abrizah, A. 2010. Populating Institutional Repository: Faculty's Contribution and Roles of Librarians. BACA: Jurnal Dokumentasi dan Informasi, Vol.31(1): 10-11.

Matthew B Miles \& A. Michael Huberman. 1992. Qualitative Data Analysis: A Source Book of New Methods. New York: McGraw Hills.

Pendit, Putu Laxman. 2003. Penelitian Ilmu Perpustakaan dan Informasi: Suatu Pengantar Diskusi Epistemologi dan Metodologi. Jakarta: Universitas Indonesia.

Pendit, Putu Laxman. 2007. Perpustakaan Digital: Perspektif Perpustakaan Perguruan Tinggi Indonesia. Jakarta: Sagung Seto.

Rowley, Jennifer. 1998. The Electronic Library, 4th ed. London: Library Association Publishing.

SPARC \& Crow, Raym. 2002. SPARC Institutional Repository Checklist \& Resource Guide Prepared by Raym Crow, SPARC Senior Consultant SPARC Institutional Repository Checklist \& Resource Guide. Washington: Publishing, The Scholarly Coalition and Academic Resources.

Sugiyono. 2013. Metode Penelitian Kuantitatif, Kualitatif, dan R\&D. Bandung: Alfabeta.

Sulistyo-Basuki. 2006. Metode Penelitian. Jakarta: Wedatama Widya Sastra dan Fakultas Ilmu Pengetahuan Budaya Universitas Indonesia.

Suwardi. 2014. Peran Pustakawan dalam Pengembangan. Visi Pustaka, 16, April.

Universitas Diponegoro. 2017. Undip Institutional Repository (UNDIP-IR). Di http://eprints.undip.ac.id/.

Waters, Donald J. 1998. What Are Digital Libraries? CLIR Issues Number 4 (July/Agustus). Di https://www.clir.org/1998/07/clir-issues-number-4/\#dlf. 